\title{
Phylogenetic clustering found in lichen but not in plant communities in European heathlands
}

\author{
I. Geedicke ${ }^{1,2}$, M. Schultz ${ }^{1}$ B. Rudolph ${ }^{1}$ and J. Oldeland ${ }^{1}$ \\ ${ }^{1}$ Biodiversity, Evolution and Ecology of Plants, Biocentre Klein Flottbek and Botanical Garden, \\ University of Hamburg, Ohnhorststr. 18, 22609 Hamburg, Germany \\ ${ }^{2}$ Corresponding author. Email: ina.geedicke@students.mq.edu.au
}

Keywords: Heathland, Historical land use, Lüneburger Heide, Lichen, MPD, Phylogenetic community structure, Phylogenetic diversity, Rarefaction, Species richness.

\begin{abstract}
Species richness is a widespread measure to evaluate the effect of different management histories on plant communities and their biodiversity. However, analysing the phylogenetic structure of plant communities could provide new insights into the effects of different management methods on community assemblages and provide further guidance for conservation decisions. Heathlands require permanent management to ensure the existence of such a cultural landscape. While traditional management with grazing is time consuming, mechanical methods are often applied but their consequences on the phylogenetic community assemblages are still unclear. We sampled 60 vegetation plots in dry sandy heathlands (EU habitat type 2310) in northern Germany stratified by five different heathland management histories: fire, plaggen (turf cutting), mowing, deforestation and intensive grazing. Due to the distant relationship of vascular plants and lichens, we assembled two phylogenetic trees, one for vascular plants and one for lichens. We then calculated phylogenetic diversity (PD) and measures of phylogenetic community structure for vascular plant and lichen communities. Deforested areas supported significantly higher PD values for vascular plant communities. We found that PD was strongly correlated with species richness (SR) but the calculation of rarefied PD was uncorrelated to SR leading to a different ranking of management histories. We observed phylogenetic clustering in the lichen communities but not for vascular plants. Thus, management by mowing and intensive grazing promotes habitat filtering of lichens, while management histories that cause greater disturbance such as fire and plaggen do not seem to affect phylogenetic community structure. The set of management strategies fulfilled the goals of the managers in maintaining a healthy heathland community structure. However, management strategies that cause less disturbance can offer an additional range of habitat for other taxonomic groups such as lichen communities.
\end{abstract}

Abbreviations: PD - Phylogenetic Diversity; VNP - NGO Verein Naturschutzpark; rPD - rarefied PD; SR - Species Richness; MPD - Mean Pairwise phylogenetic distance; NRI - Net relatedness index.

\section{Introduction}

For centuries heathland agriculture was an important farming system to make use of the poor soil in northwestern Europe (Bossuyt et al. 2001). The traditional low-intensity management with grazing, fire and mowing promoted the development of unique plant communities adapted to low nutrient, acidic soil and recurring damage by browsing and trampling (Webb 1998). In the $19^{\text {th }}$ century, with the introduction of chemical fertilizers, the agricultural use of heathlands was gradually abandoned, resulting in a rapid decrease of heathland and increase of intensively managed monocultures (Moore 1962, Webb and Vermaat 1990). Today the remaining heathlands in Europe are found in nature reserves which strive to restore and maintain the high diversity of specific plant and animal species. Heathlands are one of the principal semi-natural landscapes in Europe and are considered to have a high conservation and cultural value (Webb 1998).

The diversity of heathland plants is strongly dependent on the life cycle of the most dominant plant Calluna vulgaris. Its life cycle can be categorized into four stages: pio- neering, building, mature and decaying (Barclay-Estrup and Gimingham 1969). The first three stages show the highest diversity in vascular plants, bryophytes and lichen communities and is the intended status for conservation managers (Keienburg and Prüter 2006), while the last stage is characterized by loss of species diversity and will lead to an undesired succession into forests. Because heathlands are associated with thousands of years of agricultural practices, their unique botanical diversity excludes regrowth of trees (Piessens et al. 2005). Since traditional management methods are too labour intensive, they are supplemented with modern machines such as mowers and turf cutters. However, mechanical methods are not able to produce the highly diverse mosaic of different heathland stages which was the case in traditionally smallscale managed heathland (Webb 1998). In contrast to traditionally managed heathlands in the $19^{\text {th }}$ century, most patches of heathland today are in the same growth stage, which reduces its original diversity (Keienburg and Prüter 2006). It has been shown that different management strategies affect the species diversity of higher plants emphasizing that grazing with livestock produces a greater habitat diversity than other 
management approaches such as burning or cutting (Lake et al. 2001).

Assessing plant diversity and community structure can provide a better insight into the impact of management history on heathland. While most studies focus on species richness to measure biodiversity, community phylogenetic information might lead to a more detailed knowledge into heathland biodiversity and community structures. Phylogenetic diversity (PD) is a measure of diversity that takes into account the phylogenetic relationships between taxa (Faith et al. 2004; Rodrigues et al. 2005) and is based on phylogenetic relations among any set of taxonomic levels (Faith 1992). PD is calculated as the distance between all taxa on a phylogenetic tree of a certain community summarized by the branch lengths on the path between them (Faith 1992). The diversity measure PD has recently been extended to multiple measurements using PD in their functions while adjusting other parameters such as species abundances (Helmus et al. 2007; Webb et al. 2002) and phylogenetic tree shape (Cadotte et al. 2010). The PD and its related metrics, which we will refer to as phylogenetic patterns for simplicity, have been used to improve the understanding of community assemblages, as well as their composition and diversity (Webb 2000, Cavender-Bares et al. 2009, Cadotte et al. 2010). Phylogenetic differences are likely a proxy for the degree of ecological similarity caused by competitive exclusion or environmental filtering (Dinnage 2009). Environmental filtering, or habitat filtering can lead to clustering, where a community with more closely related species than expected, is encountered, because it is thought that only conserved characters will be tolerant to unfavourable abiotic conditions. On the contrary, the occurrence of less closely related species would be classified as phylogenetically overdispersed and can be explained by competitive exclusion, leading to the exclusion of species with similarity in their conserved characters (Vamosi et al. 2009). Dinnage (2009) showed that recently disturbed agricultural fields were phylogenetically clustered, while old abandoned agricultural fields were not. Constant phylogenetical clustering of vascular plants was observed by Letten et al. (2014) for a 21 year time series in fire-prone heathlands in New South Wales, Australia. Egorov et al. (2014) also found significant phylogenetic clustering in heathlands due to different land use intensities, including mowing and grazing. It is still debated whether phylogenies can be used to explore patterns of competition or ecological filtering (Gerhold et al. 2015; Mayfield and Levine, 2010). Still, they might explain what processes lead to the structure of a certain community and whether evolutionary relationships among community members affect other ecological processes (Cadotte et al. 2008).

There is support to the argument that phylogenetic diversity has a higher utility than species richness as a conservation criterion for management decisions (Faith 1992, Vamosi et al. 2009). Previous studies have been conducted only in a small number of ecosystems and often have not taken into account different management strategies of conservation managers. In particular, there has been no investigation of phylogenetic patterns due to different management histories in heathlands. Today, anthropogenic heathland in Germany is almost exclusively found in nature reserves and requires permanent management to ensure its existence. Thus heathlands are particularly valuable for conservation. Only a few studies have included multiple taxonomic groups (vascular plants, lichen and bryophytes) while a comparison of management histories in relation to phylogenetic measures for lichen and plant communities is missing. It is unclear whether PD and species richness would lead to a different ranking of managed heathlands or if their strong correlation would result in the same ranking. Furthermore, the recent possibility of calculating a rarefied PD (Nipperess and Matsen 2013) was little explored for the comparison of communities. Finally, it is unclear whether different management strategies for heathland habitat do lead to specific phylogenetic community patterns.

The purpose of this study was to analyse the effects of heathland management on phylogenetic diversity. We analysed two taxonomic groups, vascular plants and lichens and compared the effects of five different management strategies. Specifically, we asked $(i)$ whether PD and species richness result in different rankings of plant and lichen communities and (ii) whether a rarefied version of PD results in a different ranking compared to standard PD analysis. Further, we tested (iii) whether different management strategies act as a filter to lichen or plant communities, and thus might lead to phylogenetic clustering and what does this means for European heathland conservation.

\section{Material and methods}

\section{Study site and sampling design}

The largest heathland in northwest Germany, also known by the name Lüneburger Heide, is an anthropogenic landscape formed by agriculture and grazing of livestock for hundreds of years. It is located in the northeastern part of Lower Saxony, $40 \mathrm{~km}$ south of Hamburg, Germany (Fig.1). The climate is Atlantic with $854 \mathrm{~mm}$ annual precipitation (Keienburg and Prüter, 2006). The average temperature is $16.6{ }^{\circ} \mathrm{C}$ in summer and $1.4{ }^{\circ} \mathrm{C}$ in winter with an average annual temperature of $9{ }^{\circ} \mathrm{C}$. The total area of the nature reserve covers 23440 ha of which 5100 ha is dry sandy heathland (EU habitat type 2310) characterized by Genisto pilosaeCallunetum communities on acidic soil (Mertz, 2002). The NGO Verein Naturschutzpark (VNP) manages the anthropogenic heathlands using traditional and optimized methods. The present maintenance of heathland mimics the effect of traditional heathland agriculture and thus aims at nutrient discharge from soil (Lütkepohl and Kaiser 1997, Keienburg and Prüter 2006).

For this study, we selected five management histories that are commonly applied to dry heathland by the VNP: plaggen, fire, mowing, grazing and deforestation. The first three are mechanical methods, where plaggen is characterized by the complete mechanical removal of organic surface material, also described as turf cutting. Fire management is only carried out in winter to ensure controlled burning of the chosen sites and mowing is applied in summer and winter using large 


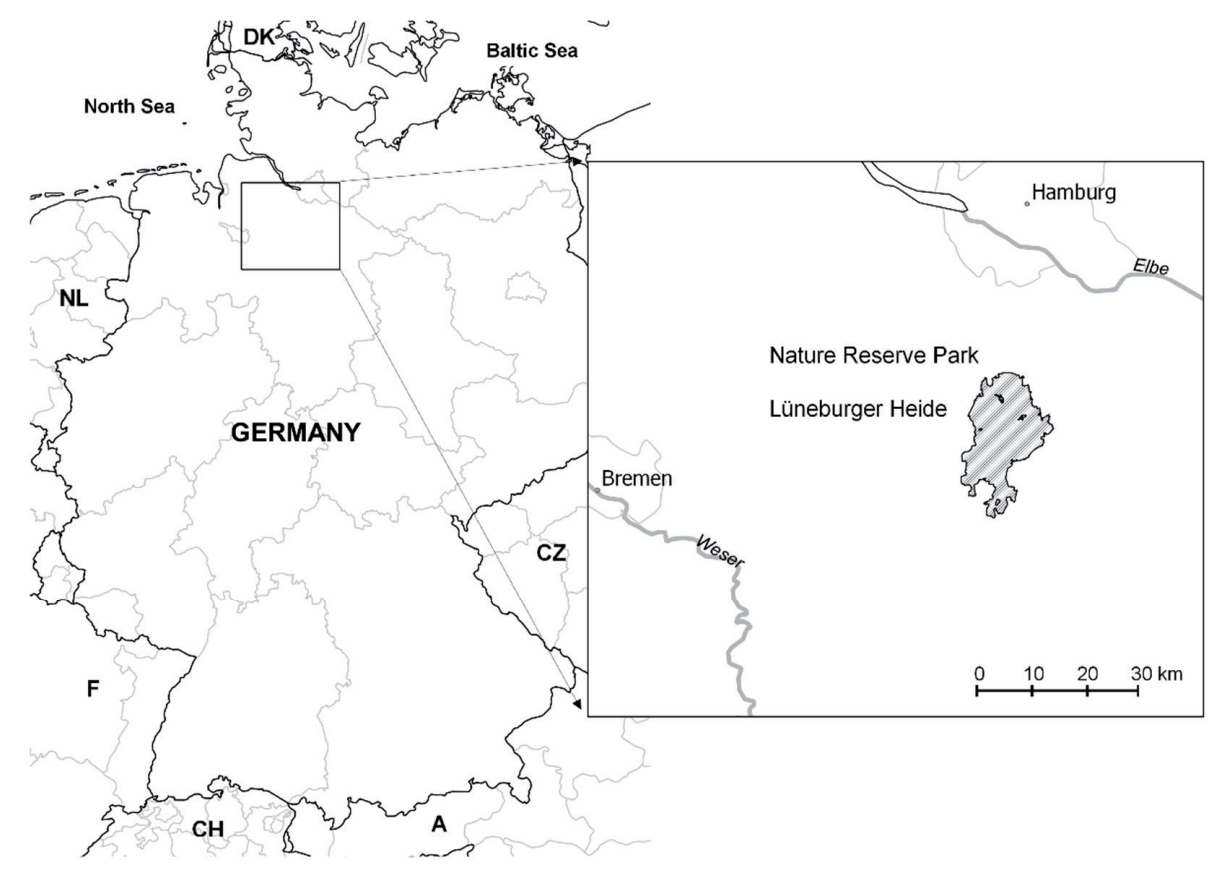

Figure 1. Location of the study site in the nature reserve park "Lüneburger Heide". The park is located 40 $\mathrm{km}$ south of Hamburg, in north-west Germany.

motorized mowers (Keienburg and Prüter 2006). To investigate the management impact of grazing on the traditional heathland, we also analyzed heathlands close to sheep stables that are managed by intensive grazing exclusively. The fifth management history included two former spruce groves, deforested in 2009 and overgrown by C. vulgaris. All sites were chosen to have been managed in winter 2009 to 2010 to ensure an equal succession rate following the application of each management method. The study took place in August 2014 and C. vulgaris was therefore in its late pioneer life stage (Barclay-Estrup and Gimingham 1969) when diversity in vascular plant, lichen and bryophyte communities is assumed to be highest. The vegetation of the five management histories was assessed using $3.3 \mathrm{~m} \times 3.3 \mathrm{~m}$, i.e., $10 \mathrm{~m}^{2}$ vegetation plots. In total, we sampled 60 plots with twelve plots per management type and listed all occurring plant and lichen species. Species abundance was estimated following the decimal scale of Londo (1976). The plots distribution was determined using a random stratification based on polygon shape files representing management histories in a geographic information system provided by the VNP.

\section{Molecular analysis}

To estimate phylogenetic trees, sequences of the nuclear internal transcribed spacer (ITS) and the large subunit of the Ribulose-1,5-bisphosphat-carboxylase/-oxygenase $(r b c \mathrm{~L})$ of the chloroplast genome were analysed. In total the vegetation list contained 77 species. We obtained 37 sequences from vascular plants and 31 lichen sequences from the GenBank (Table A1). Five sequences of vascular plants and four sequences of lichen species were produced de novo (Table A2).

The genomic DNA was isolated with the innuPREP Plant DNA Kit (Analytic Jena AG, Jena, Germany). The genes were amplified following the standard PCR protocol of
CCDB (Kuzmina and Ivanova 2011) for rbcL analysis while Rohwer's (2009) described methodology for ITS sequencing was applied for the lichen samples. The primers used in this study are shown in Table A3. Sequencing was performed on the automated sequencer 3500 Genetic Analyzer (Thermo Fisher Scientific, Inc.; Waltham, Ma USA) as described in Rohwer et al. (2014). The genetic regions were sequenced forward and reverse.

\section{Phylogenetic analysis}

Due to the distant relationship of vascular plants and lichens, we decided to assemble two phylogenetic trees, one for vascular plants and one for lichens. A composition of the two trees would result in an important loss of branch length information between the two plant groups and potentially lead to misleading conclusions of phylogenetic diversity.

The forward and reverse sequences were aligned, edited manually and merged into consensus sequences using the software BioEdit (Hall 1999). All sequence data, including sequences from GenBank, were aligned using MEGA 6 (Tamura et al. 2013) and controlled manually. The molecular tree of vascular plants was based on Bayesian interference using MrBayes version 3.2 (Hülsenbeck and Ronquist 2001, Ronquist and Hülsenbeck 2003). The Markov Chain Monte Carlo (MCMC) algorithm was used in two simultaneous runs for 10 million generations, with four stepwise heated chains and starting from random trees. The remaining trees were used to construct $50 \%$ majority rule consensus trees (Figure B1).

For lichens a composite tree (Figure B2) was created manually and adjusted according to recently published phylogenies (Helms et al. 2003, Schmull et al. 2011, Prieto and Wedin 2013) as a backbone. In addition, other phylogenetic 
studies of the Cladoniaceae family (Stenroos 2002, Fontaine et al. 2010, Pino-Bodas et al. 2013) were included. No phylogenetic analysis was available for some species of the genus Cladonia: Cladonia bellidiflora, C. glauca and C. ramulo$s a$. For those species a phylogeny for all Cladonia species was calculated using the www.phylogeny.fr online platform (Dereeper et al. 2008). The combination of literature and molecular data to construct the lichen tree required an algorithm to calculate the branch lengths. The algorithm of phylogeny construction developed by Grafen (1989) assumes that the number of nodes common between two species correlates to the evolutionary time before the pair's last common ancestor. Helmus (2007) compared three methods for branch length calculation leading to similar results, including the Grafen (1989) approach. This algorithm is implemented in R statistical environment (R Core Team, 2014), as the function "corGrafen" found in the package "ape" (Paradis et al. 2004).

\section{Statistical analysis}

Phylogenetic Diversity (PD) and rarefied Phylogenetic diversity $(r P D)$. To obtain a preliminary overview of the phylogenetic diversity of the vegetation assemblages in relation to the five different management histories using the two phylogenetic trees, PD was calculated with Faith's PD index (Faith, 1992) using the R package "picante" (Kembel et al. 2010). Faith's PD takes the generated phylogenetic tree as a blueprint and calculates the sum of the branch lengths in the minimum spanning path for a subset of taxa, co-occurring in one management type. Further, we compared the observed PD values to the standardized effect size of PD (ses PD) which was based on random PD values generated by a null model (function ses.pd(), null model = taxa.labels). As phylogenetic diversity increases with increasing sampling efforts, the comparison of the phylogenetic diversity of communities is not straightforward when sample sizes differ. Often it leads to a strong correlation of PD to species richness (SR). To standardize PD to a set of species, we determined the minimum number of species $\left(\mathrm{n}_{\min }=2\right)$ found across sites and rarefied the sites to that number of species. The rarefied PD (rPD) was calculated using the R function "Phylorare" by Nipperess and Matsen (2013).

In order to identify significant differences in PD and rPD between the management histories a multiple comparisons of medians using a generalized linear model (GLM) and a Kruskal-Wallis test was employed due to lack of normality, using the R package "pgirmess" (Giraudoux 2009).

Phylogenetic Clustering vs. Overdispersion. The phylogenetic structure within the different management histories was tested by comparing the mean pairwise phylogenetic distance (MPD) of the species found in each of the twelve plots per management strategy against the MPD values obtained under a null model (model $=$ taxa.labels). To construct the null model the species labels were reshuffled 999 times across the phylogenetic tree to hold species richness of regions and species turnover among them constant (Webb et al. 2008). The applied community matrix consisted of the abundance estimation of species recorded in the plot. A p-value $<0.05$ indicates a significant clustering while a p-value $>0.95$ indicates a significant overdispersion (Webb et al. 2008). To account for the possible different species numbers due to the low amount of plots, i.e. twelve plots, per treatment, the net relatedness index (NRI) was calculated (Webb 2000, Webb et al. 2002). The NRI is a standard effect size measure that standardizes the differences between the average phylogenetic distances in the observed and null communities by the standard deviation of phylogenetic distances in the null communities. NRI increases proportionally with clustering and becomes negative with overdispersion (Webb et al. 2002). Previous studies have shown that NRI is generally biased towards detecting clustering due to the branching structure of phylogenies (Cooper et al. 2008). Nevertheless, the NRI usually shows similar results as the MPD randomization test, and therefore we interpreted both for patterns of phylogenetic clustering or overdispersion.

\section{Results}

\section{Phylogenetic diversity}

For both phylogenetic trees, a high number of SR resulted in high PD values, while the highest values of PD and SR were found for deforestation for both lichen and vascular plant assemblages. This observation was supported by testing Pearson's product moment correlation coefficient for PD and SR. Both assemblages showed a high correlation between PD and SR (vascular plants: $r=0.98$, lichen: $r=0.86$ ).

The results of the GLM and Kruskal-Wallis analysis of PD and SR showed significant differences $(p \leq 0.001)$ between fire management and all other management histories for vascular plants (Table 1). Additionally, the vascular plant assemblages showed a significant difference in PD and SR with higher values for deforestation management compared to the other management types. However, standardized effect sizes of PD showed no significant difference ( $p$ PD, Table 1) between observed PD values and the randomized PD values obtained by the null model suggesting no clustering effect in vascular plant communities on all management histories. In lichen communities, no significant differences between the management histories could be obtained analysing PD values but compared to the null model generated random PD values, significantly lower values ( $\mathrm{p}$ PD, Table 1 ) were observed for areas managed by mowing.

While PD was strongly correlated with SR, no correlation of $r P D$ and SR was found (vascular plants: $r=-0.24$, lichen: $r$ $=0.03$ ). The calculation of rPD resulted in a different ranking of the management histories based on diversities (Table 1). The results of Kruskal-Wallis analysis showed no significant differences between the management histories for lichen and vascular plants. Rarefied PD was highest on management for vascular plants under the fire and deforestation management strategy, while Faith's PD showed deforestation only had highest PD values. The lichen tree also showed highest rPD values for fire management and the rankings for the different management strategies varied between $\mathrm{PPD}$ and PD. 
Table 1. Calculation of Faith's phylogenetic diversity (PD), the randomized phylogenetic diversity (rPD), species richness (SR) and the average of $\mathrm{SR}\left(\mathrm{SR}_{\mathrm{m}}\right)$ of the lichen and vascular plant assemblages for the five management strategies analysed in the Lüneburger Heide. The interquartile range (IQR) for SR and for PD the standard effect size (ses PD) and the p-values of PD in relation to a null model was calculated marked with asterisk $(*)$. Significance values between the management histories are highlighted using small lowercase letters in front of the management types.

\begin{tabular}{|c|c|c|c|c|c|c|}
\hline & Management Type & $\mathrm{SR}_{\text {Total }}$ & $\mathrm{SR}_{\mathrm{m}}$ & $\mathrm{rPD}$ & PD & ses PD \\
\hline \multirow[t]{5}{*}{ Vascular Plants } & Fire & 16 & ${ }^{\mathrm{ab}} 4.75$ & ${ }^{\mathrm{a}} 1.74$ & ${ }^{a b} 3.13$ & ${ }^{a b}-0.30$ \\
\hline & Deforestation & 33 & ${ }^{\mathrm{a}} 10.58$ & ${ }^{\mathrm{a}} 1.74$ & ${ }^{\mathrm{a}} 6.26$ & ${ }^{a b}-0.66$ \\
\hline & Mowing & 15 & ${ }^{c} 4.58$ & ${ }^{\mathrm{a}} 1.71$ & ${ }^{c} 3.24$ & ${ }^{a b}-0.20$ \\
\hline & Plaggen & 10 & ${ }^{\mathrm{bc}} 2.42$ & ${ }^{\mathrm{a}} 1.70$ & ${ }^{\mathrm{bc}} 3.13$ & ${ }^{\mathrm{a}} 0.19$ \\
\hline & Intensive Grazing & 18 & $\mathrm{abc} 5.00$ & ${ }^{\mathrm{a}} 1.68$ & bc 3.47 & ${ }^{b}-0.27$ \\
\hline \multirow[t]{5}{*}{ Lichen } & Fire & 31 & a 7.58 & ${ }^{\mathrm{a}} 1.55$ & a7.89 & $\mathrm{a}-1.47$ \\
\hline & Deforestation & 35 & ${ }^{\mathrm{a}} 9.67$ & ${ }^{\mathrm{a}} 1.48$ & ${ }^{\mathrm{a}} 9.18$ & ${ }^{a}-0.83$ \\
\hline & Mowing & 29 & a9. 98 & ${ }^{\mathrm{a}} 1.41$ & ${ }^{\mathrm{a}} 5.26$ & ${ }^{* * a} \mathrm{a}-3.86$ \\
\hline & Plaggen & 30 & ${ }^{\mathrm{a}} 12.08$ & ${ }^{\mathrm{a}} 1.47$ & ${ }^{\mathrm{a}} 7.79$ & ${ }^{\mathrm{a}}-1.43$ \\
\hline & Intensive Grazing & 35 & a7.17 & ${ }^{\mathrm{a}} 1.42$ & aа 8.96 & a -1.05 \\
\hline
\end{tabular}

Signif. codes: ' $* * *$ ' $<0.001$ ' $* *$ ' $<0.01$ ' $*$ ' $<0.05$

Table 2. Phylogenetic pattern calculated using the observed mean pairwise phylogenetic distances (MPD). The number of taxa per management type and phylogenetic tree equals the number of species (N). Calculated are the randomized MPD (rndMPD), the standard deviation of the rndMPD (sd.rndMPD), and the net relatedness index (NRI). The p-value and the suggested pattern of the phylogenetic structure for each study site reflect the departure of the observed MPD value from the null model. Phylogenetic trees and the respective management type are highlighted in grey where patterns where observed.

\begin{tabular}{|c|c|c|c|c|c|c|c|c|}
\hline & Management Type & $\mathrm{N}$ & NRI & MPD & $\operatorname{ranMPD}$ & sd.ranMPD & $\mathrm{P}$ & Pattern \\
\hline \multirow[t]{5}{*}{ Vascular Plants } & Fire & 16 & -0.56 & 0.59 & 0.49 & 0.18 & 0.78 & no pattern \\
\hline & Deforestation & 33 & 0.21 & 0.36 & 0.38 & 0.10 & 0.46 & no pattern \\
\hline & Mowing & 15 & -0.04 & 0.08 & 0.08 & 0.03 & 0.59 & no pattern \\
\hline & Plaggen & 10 & 0.72 & 0.05 & 0.06 & 0.02 & 0.22 & no pattern \\
\hline & Intensive Grazing & 18 & -0.44 & 0.15 & 0.13 & 0.04 & 0.73 & no pattern \\
\hline \multirow[t]{5}{*}{ Lichen } & Fire & 31 & -0.66 & 0.93 & 0.84 & 0.14 & 0.73 & no pattern \\
\hline & Deforestation & 35 & 3.75 & 0.93 & 1.28 & 0.09 & 0.00 & clustering \\
\hline & Mowing & 29 & 2.61 & 0.96 & 1.25 & 0.11 & 0.01 & clustering \\
\hline & Plaggen & 30 & 1.00 & 1.11 & 1.23 & 0.12 & 0.17 & no pattern \\
\hline & Intensive Grazing & 35 & 3.17 & 0.54 & 1.08 & 0.17 & 0.00 & clustering \\
\hline
\end{tabular}

\section{Phylogenetic clustering vs. overdispersion}

Only three of the observed MPD values were significantly lower than randomized MPD values resulting in distinguishable patterns (Table 2). After matching the p-value of the MPD null model and the respective NRI values, the analysis resulted in a clustered pattern for all management histories for the lichen assemblages except for plaggen and fire managed sites. No phylogenetic clustering or overdispersion was found for the vascular plant assemblages.

\section{Discussion}

Our results confirm that different management histories, applied to maintain dry, sandy heathlands, have a significant effect on the phylogenetic structure of the plant communities but also depend strongly on the observed taxonomic group. Vascular plants responded less strongly than lichens to the applied management methods, which showed a phylogenetic clustering in less intensively managed habitats.

Different management histories seem to act as a filter on lichen assemblages. Our results showed phylogenetic cluster- 
ing in grazing, mowing and deforestation management but not for plaggen and fire. Deforestation, mowing and grazing management provide a rather intermediate form of disturbance in heathlands, where lichens seem to use the new open spaces without being removed completely from the area. The deforested areas consist of a wide range of surface types, such as small trees, dead wood and different kinds of soil types. We noted that species adapted to grow exclusively on branches (i.e., Lecanora elaechroma, Hypogymnia physodis, Xanthoria parietina) were only found in deforested areas, underpinning the result of clustering due to habitat filtering (Figure B2). On the other hand, a sub-group of the genus Cladoniacea (e.g. C. arbuscular, C. mitis, C. portentosa, C. ciliate, C. uncialis) were found on all management histories but not in deforested areas. We assume that this sub-group is specialized due to a long history of heathland management. An additional explanation of the clustering in areas managed by mowing and grazing could be the small dispersion rate (Cavender-Bares et al. 2009). Another limiting factor of lichen dispersal is that the reproduction rate of lichen is complicated due to the different reproduction systems of the two symbiosis partners and that the fungal spores have to meet the algal photobiont in order to form a new thallus (Bailey 1976). Lichens are highly specialized to surface conditions and most species will only grow on a certain surface (i.e. dead wood, stone). Therefore, we would have assumed that strong disturbance due to fire or plaggen would result in habitat filtering and thus result in a clustered phylogenetic pattern (Webb et al. 2002). However, in our study management histories involving the removal of above ground plant material, such as fire and plaggen, did not favour clustering of lichen communities. One explanation for the result could be that fire and plaggen pose an extreme disturbance to the slow growing lichen communities restarting the succession of the disturbed habitat.

No phylogenetic pattern could be observed for vascular plants. Interestingly plaggen and fire had no influence on the phylogenetic community structure. Plaggen and fire result in the strongest disturbance of the management histories applied in heathlands. Although fire has been found to determine phylogenetic clustering of Australian heathlands (Letten et al. 2014), we didn't find the same effect in the central European heathlands. In contrast to the Australian heathlands, where fire is a common environmental factor, in the Lüneburger Heide fire is human induced and only applied in small patches $\left(50 \mathrm{~m}^{2}\right)$ and not on a regular time scale (Keienburg and Prüter 2006). Therefore, burning the same area every 10 to 15 years did not lead to adaptations to fire as a conserved trait in habitat-use to abiotic factors, e.g., none of the observed plants do have any known fire-related traits. However, it has been shown before that several typical heath plants, such as Calluna vulgaris and Genista anglica, are promoted to germinate after burning at relatively low burning temperatures (Mallik and Gimingham 1985). Also removing above ground material and humus (plaggen) does not seem to favour closely related species. This could be explained by the fact that mechanical plaggen reduces such a large amount of plant and soil material, that resettlement of the area needs to begin anew.
Recent studies have challenged the concept tested here that phylogenetic dispersion allows inference of community assembly processes. Gerhold et al. (2015) list seven assumptions required to be true for this to occur but for all only found weak support has been reported in the literature so far and they suggest that other processes such as facilitation or even mutualism could lead to a similar phylogenetic dispersion pattern. Furthermore, Mayfield and Levine (2010), argue that the concept is not in line with modern coexistence theory and that in fact two different kinds of competitive exclusion patterns exist which might even lead to opposing results, i.e. depending on the strength of the competition it might result in phylogenetic clustering or overdispersion. The recent consensus seems to be that competitive exclusion "only sometimes eliminates more closely related taxa" (Mayfield and Levine 2010). However, we did not observe any pattern of overdispersion, only environmental filtering. Interestingly, our system is frequently disturbed, in fact potentially rendering the effects of competition to be weak. Still, our study is only a "snapshot" of a non-equilibrium system that is continuously in a state of succession. Furthermore, it can be questioned whether fine-scaled studies, like ours, can reveal any strong phylogenetic pattern (Letten et al. 2014). We thus have to be careful in the interpretation given the recent criticism.

Another approach to analyse phylogenetic pattern is the calculation of Faith's PD (Faith 1992). It shows how closely related a subset of taxa is in comparison to other communities. The calculation of PD showed significantly different values for management histories, but the PD of both vascular plant and lichen assemblages were strongly correlated with SR. This has also been observed and criticized in other publications using PD (Cadotte et al. 2008, Pienkowski et al. 1998). Thus it is questionable whether the extra effort in generating the PD data is worth it in a conservation context. Using SR and its common metrics to calculate biodiversity would have required less time and resources than calculating PD. However, there are habitats where PD is not correlated with SR and in these communities, with species that are more distantly or closely related than expected, consideration of PD can influence management and conservation decisions (Winter et al. 2013). The analysis of the standard effect sizes of PD under a null model provided us with additional information on whether our observed PD values differed from expected PD values with the same species pool. Similar to our results of NRI and MPD, we found no significant difference between expected and observed PD in vascular plants. In lichen communities, lower PD values than expected from the null model were found underpinning our findings of clustering with the NRI analysis. However the standardized effects could not detect differences between management histories because variations in the number of species per plot varies greatly (IQR, Table1). These variances might be due to environmental effects or interferences with former management histories applied to the areas. We found most prominent variances in SR in lichen communities leading us to question if the plot size of $10 \mathrm{~m}^{2}$ might have been too large for small scale lichen communities. Another attempt to analyse the phylogenetic diversity of a habitat is the calculation of the 
expected PD under rarefaction (rarefied PD, Nipperess and Matsen 2013). The algorithm for the rarefied PD calculates the values compared to the minimum number of species sampled at each management strategy and is therefore not correlated with SR. The rarefied PD revealed fire management as the strategy resulting in highest $\mathrm{PPD}$ values for both lichens and vascular plants, while calculation of PD found the deforested areas as most phylogenetically diverse. In deforested areas twice as many species were sampled compared to fire managed areas and the result that fire management leads to higher rPD values suggests a more distantly related species composition in those areas than in deforested areas. Looking at the species list of the fire managed areas at least one species was found from each clade, explaining the high rPD value. The results of PD and rPD between different management histories showed a larger variation of unrelated species for the lichen assemblage under deforestation strategy compared to fire, mowing, grazing and plaggen. The higher variability of lichen species in the deforested area could be explained by the different habitats. Lichen exclusively growing on dead wood can more commonly be found on the tree stumps in those areas. In addition, there is probably a large propagule pressure from forest dominants entering into the disturbed plots (Dinnage 2009) explaining the higher diversity.

With the sequences available at GenBank and the additional sequencing of the remaining five vascular plant species, building a phylogenetic tree for vascular plants gave a stable yet not undisputable result. The majority of phylogenetic community analysis refers to vascular plants (Vamosi et al. 2009) and the APG3 system (Stevens 2001) which is mostly used as a blueprint for their phylogenetic trees (CavenderBares et al. 2006, Verdú and Pausas 2007, Webb et al. 2008). A comparison of the vascular plant phylogenetic tree of this study to the APG3 tree showed that the assignment of species to the tips of the tree is following the APG3 system. But it seems that the basal branches of the vascular plant tree were not clearly resolved. This result might be due to the fact that only one marker was used for phylogenetic analysis of higher plants. A second marker in combination with $r b c \mathrm{~L}$ would give a better resolution at the basis and at terminal nodes of the tree.

To compose the lichen phylogenetic tree, a combination of phylogenetic analysis and literature assemblage was required. Following Webb's (2002) suggestion of assembling a cladogram manually, based on published molecular data, the final lichen phylogenetic tree was obtained. The nuclear ITS marker was not suitable to separate distantly related species from each other. Since the ITS sequence evolves at a quite fast rate, ITS seems to be more useful for analysis at generic and infrageneric level (Poczai and Hyvönen 2010). Therefore, the sequence data was only used to analyse the genus of Cladonia and Placynthiella, where literature was also not sufficient enough to build a cladogram. For future analysis, a phylogenetic tree based on de novo sequence data and more than one marker would lead to a uniform assemblage of phylogenetic trees. This could strengthen the results shown in this study. Also, an investigation about the influence of branch length calculation and dating methods (branch length vs. dated tree) would be an interesting approach in interpreting other publications on phylogenetic diversity.

\section{Conclusion}

Considering the results of phylogenetic community analysis on different management histories practiced in the heathlands of the Lüneburger Heide, deforestation provided the most diverse habitat for plants and lichen, which resulted in especially high diversity and PD values. Nevertheless, the deforested areas with tree stumps and different growth stages of Calluna vulgaris do not express the typical picture of heathlands that is sought by tourism nor conservation managers. The financing of the nature reserve park depends heavily on tourism and hence management strategies that focus on existing heathlands are important. The management of vascular plants achieves exactly what it is supposed to do: retaining a healthy heathland plant community. However, the variety of management strategies allows other organisms, such as lichen, to grow in their specialized niches. Therefore, a management strategy based on small scale deforestation, to ensure a high variety of plants and lichen, and small scale succession of overgrown heathland, to keep the balance of woodland and heathland, would provide a highly variable habitat, while intensive grazing, plaggen and mowing would support the maintenance of heathlands. Following this recommendation, it is possible to manage a heathland which does not exclusively contain the typical heather plants but also a high number of lichen species, valuable for conservation.

Acknowledgements: Many thanks to D. Nipperess for his help in the use and interpretation of the R package "phylorare" as well as to Prof. M. Leishman and Mrs. N. Mitra for polishing our English.. We also thank the VNP at the Lüneburger Heide and especially D. Mertens for the permission to work in the nature reserve park Lüneburger Heide and for his helpful comments on the local flora.

\section{References}

Bailey, R.H. 1976. Ecological aspects of dispersal and establishment in lichens. In: Brown, D.H., Hawksworth, D.L. and Bailey, R.H. (eds), Lichenology: Progress and Problems. Academic Press, London. pp. 215-247.

Barclay-Estrup, P. and Gimingham, C.H. 1969. The description and interpretation of cyclical processes in a heath community: I. vegetational change in relation to the calluna cycle. J. Ecol. 57: $737-758$

Bossuyt, B., Honnay, O., Van Stichelen, K., Hermy, M. and Van Assche, J. 2001. The effect of a complex land use history on the restoration possibilities of heathland in central Belgium. Belg. J. Bot. 134: 29-40.

Cadotte, M.W., Cardinale, B.J. and Oakley, T.H. 2008. Evolutionary history and the effect of biodiversity on plant productivity. Proc. Natl. Acad. Sci. U. S. A. 105:17012-17017.

Cadotte, M.W., Jonathan Davies, T., Regetz, J., Kembel, S.W., Cleland, E. and Oakley, T.H. 2010. Phylogenetic diversity metrics for ccological communities: integrating species richness, abundance and evolutionary history. Ecol. Lett. 13: 96-105. 
Cavender-Bares, J., Keen, A. and Miles, B. 2006. Phylogenetic structure of Floridian plant communities depends on taxonomic and spatial scale. Ecology 87: 109-122.

Cavender-Bares, J., Kozak, K.H., Fine, P.V.A. and Kembel, S.W. 2009. The merging of community ecology and phylogenetic biology. Ecol. Lett. 12: 693-715.

Cooper, N., Rodríguez, J. and Purvis, A. 2008. A common tendency for phylogenetic overdispersion in mammalian assemblages. Proc. R. Soc. Lond. B Biol. Sci. 275: 2031-2037.

Dereeper, A., Guignon, V., Blanc, G., Audic, S., Buffet, S., Chevenet, F., Dufayard, J.-F., Guindon, S., Lefort, V., Lescot, M., et al. 2008. Phylogeny.fr: robust phylogenetic analysis for the nonspecialist. Nucleic Acids Res. 36: 465-469.

Dinnage, R. 2009. Disturbance alters the phylogenetic composition and structure of plant communities in an old field system. PLoS ONE 4, e7071.

Egorov, E., Prati, D., Durka, W., Michalski, S., Fischer, M., Schmitt, B., Blaser, S. and Brändle, M. 2014. Does land-use intensification decrease plant phylogenetic diversity in local grasslands? PLOS ONE 9, e103252.

Faith, D.P. 1992. Conservation evaluation and phylogenetic diversity. Biol. Conserv. 61: 1-10.

Faith, D.P., Reid, C.A.M. and Hunter, J. 2004. Integrating phylogenetic diversity, complementarity, and endemism for conservation assessment. Conserv. Biol. 18: 255-261.

Fontaine, K.M., Ahti, T. and Piercey-Normore, M.D. 2010 Convergent evolution in Cladonia gracilis and allies. The Lichenologist 42: 323-338.

Gerhold, P., Cahill Jr, J.F., Winter, M., Bartish, I.V. and Prinzing, A 2015. Phylogenetic patterns are not proxies of community assembly mechanisms (they are far better). Funct. Ecol. 29: 600614.

Giraudoux, P. 2009. pgirmess: Data analysis in ecology. R package version 1.5.9.

Grafen, A. 1989. The phylogenetic regression. Philos. Trans. R. Soc. Lond. B Biol. Sci. 326: 119-157.

Hall, T. 1999. BioEdit: a user-friendly biological sequence alignment editor and analysis program for Windows 95/98/NT. Nucleic Acids Symp. Ser. 41: 95-98.

Helms, G., Friedl, T. and Rambold, G. 2003. Phylogenetic relationships of the Physciaceae inferred from rDNA sequence data and selected phenotypic characters. Mycologia 95: 1078-1099.

Helmus, M.R., Bland, T.J., Williams, C.K. and Ives, A.R. 2007. Phylogenetic measures of biodiversity. Am. Nat. 169: E68-E83.

Hülsenbeck, J.P. and Ronquist, F. 2001. MRBAYES: Bayesian inference of phylogeny. Bioinformatics 17: 754-755.

Keienburg, T. and Prüter, J. 2006. Naturschutzgebiet Lüneburger Heide: Erhaltung und Entwicklung einer alten Kulturlandschaft. Mitteilungen Aus NNA 17, 65.

Kembel, S.W., Cowan, P.D., Helmus, M.R., Cornwell, W.K., Morlon, H., Ackerly, D.D., Blomberg, S.P. and Webb, C.O. 2010. Picante: $\mathrm{R}$ tools for integrating phylogenies and ecology. Bioinformatics 26: 1463-1464.

Kuzmina, M. and Ivanova, N. 2011. Amplification for Plants and Fungi. Canadian Centre for DNA barcoding, Guelph, Canada.

Lake, S., Bullock, J.M. and Hartley, S. 2001. Impacts of livestock grazing on lowland heathland in the UK. Engl. Nat. Res. Rep. 422: 143.

Letten, A.D., Keith, D.A. and Tozer, M.G. 2014. Phylogenetic and functional dissimilarity does not increase during temporal heathland succession. Proc. R. Soc. Lond. B Biol. Sci. 281: 20142102.
Londo, G. 1976. The decimal scale for releves of permanent quadrats. Vegetatio 33: 61-64.

Lütkepohl, M. and Kaiser, T. 1997. Die Heidelandschaft. In: Naturschutzgebiet Lüneburger Heide: Geschichte, Ökologie, Naturschutz. Verlag H. M. Hausschild GmbH, Bremen. pp. $87-100$.

Mallik, A.U. and Gimingham, C.H. 1985. Ecological effects of heather burning: II. Effects on seed germination and vegetative regeneration. J. Ecol. 73: 633-644.

Mayfield, M.M. and Levine, J.M. 2010. Opposing effects of competitive exclusion on the phylogenetic structure of communities: Phylogeny and coexistence. Ecol. Lett. 13: 1085-1093.

Mertz, P. 2002. Pflanzenwelt Mitteleuropas und der Alpen. Nikol Verlagsgesellschaft mbH \& co.KG, Hamburg.

Moore, N.W. 1962. The heaths of dorset and their conservation. $J$. Ecol. 50: 369-391.

Nipperess, D.A. and Matsen, F.A. 2013. The mean and variance of phylogenetic diversity under rarefaction. Methods Ecol. Evol. 4: 566-572.

Paradis, E., Claude, J. and Strimmer, K. 2004. APE: analyses of phylogenetics and evolution in R language. Bioinformatics 20: 289-290.

Pienkowski, M.W., Watkinson, A.R., Kerby, G., Clarke, K.R. and Warwick, R.M. 1998. A taxonomic distinctness index and its statistical properties. J. Appl. Ecol. 35: 523-531.

Piessens, K., Honnay, O. and Hermy, M. 2005. The role of fragment area and isolation in the conservation of heathland species. Biol. Conserv. 122: 61-69.

Pino-Bodas, R., Martín, M.P., Burgaz, A.R. and Lumbsch, H.T. 2013. Species delimitation in Cladonia (Ascomycota): a challenge to the DNA barcoding philosophy. Mol. Ecol. Resour. 13: 10581068.

Poczai, P. and Hyvönen, J. 2010. Nuclear ribosomal spacer regions in plant phylogenetics: problems and prospects. Mol. Biol. Rep. 37: 1897-1912.

Prieto, M. and Wedin, M. 2013. Dating the diversification of the major lineages of Ascomycota (Fungi). PLOS ONE 8, e65576.

R Core Team 2014. R: A language and environment for statistical computing. Vienna, Austria: R Foundation for Statistical Computing.

Rodrigues, A.S.L., Brooks, T.M. and Gaston, K.J. 2005. Integrating phylogenetic diversity in the selection of priority areas for conservation: Does it make a difference? In: Purvis, A., Gittleman, J.L. and T. Brooks. (eds.), Phylogeny and Conservation. Cambridge University Press, New York. pp. 101-119.

Rohwer, J.G., Li, J., Rudolph, B., Schmidt, S.A., Werff, H. van der and Li, H. 2009. Is Persea (Lauraceae) monophyletic? Evidence from nuclear ribosomal ITS sequences. Taxon 58: 1153-1167.

Rohwer, J.G., Moraes, P.L.R.D., Rudolph, B. and Werff, H.V.D 2014. A phylogenetic analysis of the Cryptocarya group (Lauraceae) and relationships of Dahlgrenodendron, Sinopora, Triadodaphne, and Yasunia. Phytotaxa 158: 111-132.

Ronquist, F. and Hülsenbeck, J.P. 2003. MRBAYES 3: Bayesian phylogenetic inference under mixed models. Bioinformatics 19: 1572-1574.

Schmull, M., Miadlikowska, J., Pelzer, M., Stocker-Wörgötter, E., Hofstetter, V., Fraker, E., Hodkinson, B.P., Reeb, V., Kukwa, M., Lumbsch, H.T., et al. 2011. Phylogenetic affiliations of members of the heterogeneous lichen-forming fungi of the genus Lecidea sensu Zahlbruckner (Lecanoromycetes, Ascomycota). Mycologia 103: 983-1003. 
Stenroos, S. 2002. Phylogeny of the genus Cladonia s.lat. (Cladoniaceae, Ascomycetes) inferred from molecular, morphological, and chemical data. Cladistics 18: 237-278.

Stevens, P.F. 2001. Angiosperm phylogeny website. Version 13, October 2014.

Tamura, K., Stecher, G., Peterson, D., Filipski, A. and Kumar, S. 2013. MEGA6: molecular evolutionary genetics analysis version 6.0. Mol. Biol. Evol. 30: 2725-2729.

Vamosi, S.M., Heard, S.B., Vamosi, J.C. and Webb, C.O. 2009. Emerging patterns in the comparative analysis of phylogenetic community structure. Mol. Ecol. 18: 572-592.

Verdú, M. and Pausas, J.G. 2007. Fire drives phylogenetic clustering in Mediterranean Basin woody plant communities. J. Ecol. 95: 1316-1323.

Webb, C.O. 2000. Exploring the phylogenetic structure of ecological communities: an example for rain forest trees. Am. Nat. 156: 145-155.

Webb, N.R. 1998. The traditional management of European heathlands. J. Appl. Ecol. 35: 987-990.

Webb, N.R. and Vermaat, A.H. 1990. Changes in vegetational diversity on remnant heathland fragments. Biol. Conserv. 53: 253264.

Webb, C.O., Ackerly, D.D., McPeek, M.A. and Donoghue, M.J. 2002. Phylogenies and community ecology. Annu. Rev. Ecol. Syst. 33: 475-505.

Webb, C.O., Ackerly, D.D. and Kembel, S.W. 2008. Phylocom: software for the analysis of phylogenetic community structure and trait evolution. Bioinformatics 24: 2098-2100.
Winter, M., Devictor, V. and Schweiger, O. 2013. Phylogenetic diversity and nature conservation: where are we? Trends Ecol. Evol. 28: 199-204.

Received June 17, 2016

Revised November 14, 2016 Accepted November 30, 2016

\section{Electronic Appendices}

\section{Appendix A}

Table A1. Sequence Data obtained from GenBank.

Table A2. Vascular plants and lichens, that where sequenced using the listed primers. Samples were gathered at the study site "Lüneburger Heide".

Table A3. Primers and primer sequences. The $r b c \mathrm{~L}$ primers where used for plant DNA sequencing and ITS primers for lichens.

\section{Appendix B}

Figure B1. Phylogenetic tree of all vascular plants obtained at the study site.

Figure B2. Phylogenetic tree of all lichens obtained at the study site.

The file may be downloaded from www.akademiai.com. 